\title{
A case of recurrent biliptysis
}

\begin{abstract}
Velayutham Vimalraj, MS, Satyanesan Jeswanth, MCh, Eswaran Selvakumar, MS, Damodaran Jyotibasu, MS, Shanmugasundaram Rajendran, MCh, Palaniappan Ravichandran, MCh, Tirupporur Govindaswamy Balachandar, MCh, Devy Gounder Kannan, MCh, and Rajagopal Surendran, MCh, Chennai, India
\end{abstract}

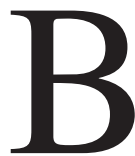
ronchobiliary fistulas (BBFs), communications between the bronchus and the biliary system, are rare. ${ }^{1}$ We report a case of persistent biliptysis that necessitated hepatectomy. To our knowledge, this is the first reported case of $\mathrm{BBF}$ requiring hepatectomy as a treatment.

\section{Clinical Summary}

A 30-year-old man was seen with biliptysis and chest pain of 3 years' duration. History included percutaneous liver abscess drainage in 2002 in a district hospital, after which biliptysis developed. In 2003, the patient underwent endoscopic retrograde cholangiography and stenting, after which he was symptom free for only 3 months. In May 2004, he underwent exploratory thoracotomy with hepatobronchial disconnection; he was apparently all right for 2 weeks and then had biliptysis again. Endoscopic retrograde cholangiography and stenting were done 3 weeks after the exploratory thoracotomy. In December 2004, biliptysis developed once more; endoscopic retrograde cholangiography with stent exchange was done, but the biliptysis persisted.

From the Department of Surgical Gastroenterology and Centre for G.I. Bleed \& Division of Hepato Biliary Pancreatic Diseases, Government Stanley Medical College Hospital, Chennai, Tamilnadu, India.

Received for publication Dec 8, 2006; accepted for publication Jan 8, 2007

Address for reprints: R. Surendran, MCh, Head of Department, Department of Surgical Gastroenterology, Government Stanley Medical College Hospital, Chennai-600001, Tamilnadu, India (E-mail: Stanleygastro@yahoo. com).

J Thorac Cardiovasc Surg 2007;133:1662-3

$0022-5223 / \$ 32.00$

Copyright $\odot 2007$ by The American Association for Thoracic Surgery doi:10.1016/j.jtcvs.2007.01.047
The patient was referred to our hospital in May 2005. The alkaline phosphatase level was $354 \mathrm{IU} / \mathrm{L}$ (reference range 100-290 IU/L). Magnetic resonance imaging and magnetic resonance cholangiography showed the $\mathrm{BBF}$

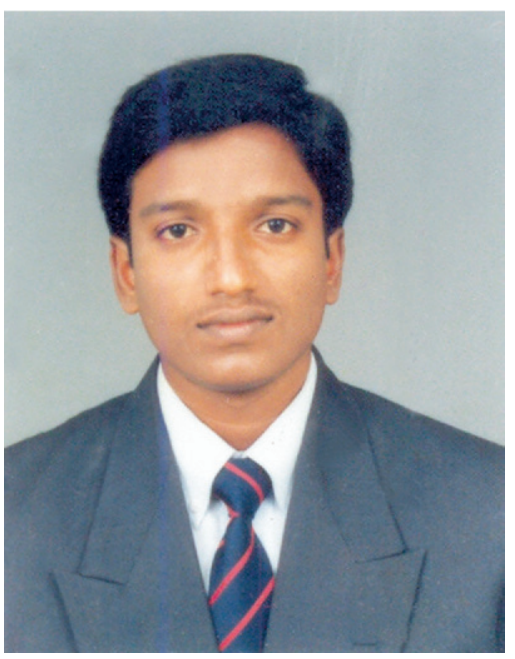

Mr Vimalraj and also a shrunken cavity in the atrophied right lobe and a hypertrophied left lobe (Figure 1). Laparotomy revealed a $7 \times 3-\mathrm{cm}$ residual abscess cavity in the atrophic right lobe of the liver communicating with the right pleural cavity and right bronchus through the diaphragm. The patient underwent a right hepatectomy. Two plastic stents in the common bile duct were removed through a choledochotomy, which was closed over a $12 \mathrm{~F}$ T-tube. The T-tube was removed at 3 months, after a T-tube cholangiogram was performed. Computed tomographic scan 1 year after the procedure revealed a well-hypertrophied residual left lobe of liver (Figure 2). The patient is completely symptom free and receiving follow-up.

\section{Discussion}

Several mechanisms can result in BBFs. One mechanism involves biliary obstruction, which produces an inflammatory reaction in the subdiaphragmatic space, with subsequent rupture into the bronchial system. Another mechanism is erosion of abscesses or hydatid cysts through the diaphragm into the pleural cavity and adjacent bronchial tree to create a fistula. ${ }^{2}$

Endoscopic retrograde cholangiography may demonstrate the fistulous tract and identify distal biliary obstruction, crucial for the persistence of BBF. Furthermore, endoscopic sphincterotomy may be undertaken during this study. Endoscopic sphinc-

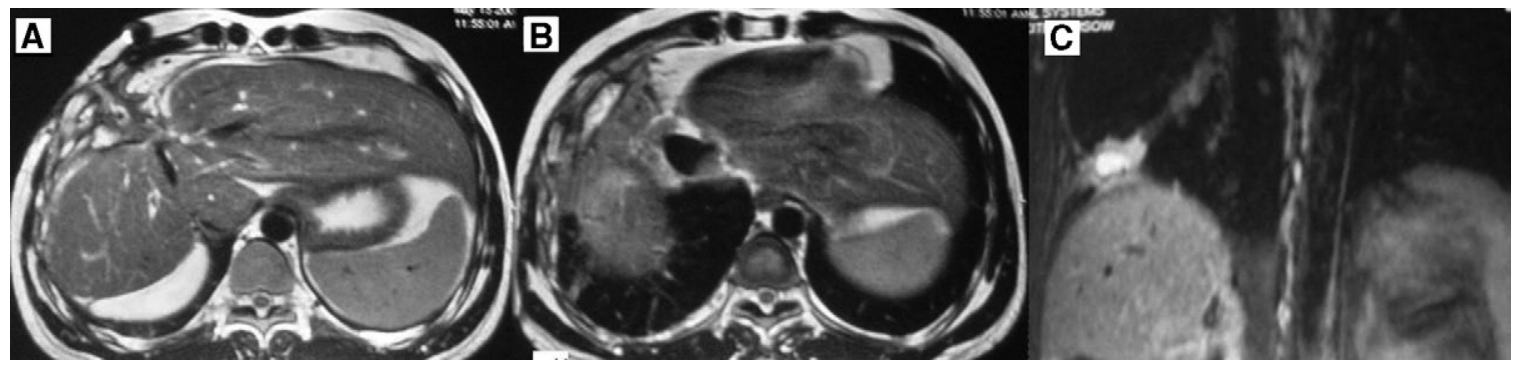

Figure 1. Magnetic resonance imaging and magnetic resonance cholangiography show bronchobiliary fistula and also shrunken cavity in atrophied right lobe and hypertrophied left lobe. 


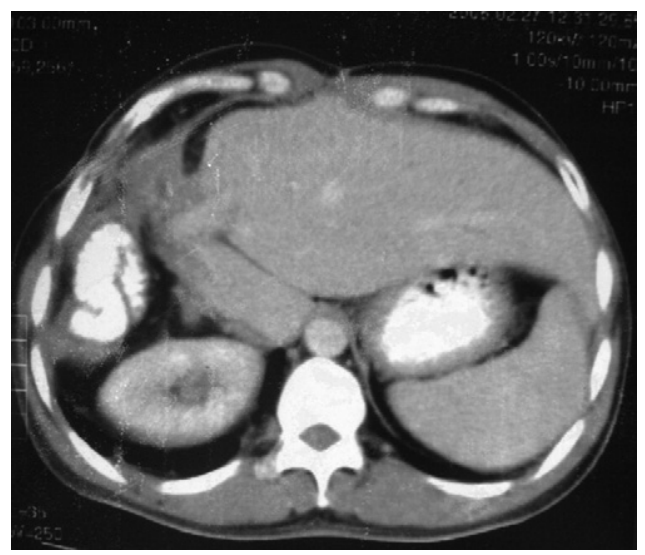

Figure 2. Computed tomographic scan 1 year after procedure reveals well-hypertrophied residual left lobe of liver.

terotomy is recommended when there is persistence of symptoms within 72 to 96 hours of the placement of tube thoracostomy or percutaneous drainage of sepsis. Endoscopic sphincterotomy alone has been applied successfully to treat $\mathrm{BBF}$ as a complication of gallstones, hepatic trauma, and biliary surgical procedures. ${ }^{1}$

The persistence of a BBF is widely attributed to the differential pressure gradient between the common bile duct and the sphincter of Oddi. ${ }^{3}$ When this pressure gradient is effectively eliminated (as after an endoscopic sphincterotomy), the output of the BBF is dramatically reduced, thus facilitating rapid closure of the fistula. The consistent and enduring success of endoscopic sphincterotomy in the management of BBF lends credence to the role of differential biliary pressures in the persistence of this type of fistula. Although there is little doubt that other factors may be implicated in the continuance of a $\mathrm{BBF}$, the most notable of which appears to be sepsis, the importance of these factors cannot be conclusively established. ${ }^{4}$ Our patient underwent two sessions of endoscopic stenting, which probably failed because of persistent sepsis that was left undrained.

Definitive surgery for a BBF should have two components, first the management of abdominal pathology with biliary diversion or stents to relieve the obstruction and second the excision of the fistula tract and lung tissue destroyed by the necrotizing bronchopneumonia. This may entail a wedge resection, segmentectomy, or lobectomy. As an adjunct to resection, viable tissue can be interposed between the lung and the diaphragmatic defect. Tissue used for the interposition most frequently is muscle or fat. Early surgical intervention has been advocated to circumvent the respiratory compromise to which these fistulas are liable to predispose..$^{2,5}$

The presence of a large cavity in an atrophic right lobe of liver caused the persistent biliptysis in this patient despite hepatobronchial disconnection by excision of the tract. Right hepatectomy was done to remove completely the large cavity in the atrophic right lobe.

BBFs are usually managed with a conservative and endoscopic approach. Surgery should be reserved for persistence of symptoms after exhaustion of this approach.

\section{References}

1. Singh B, Moodley J, Sheik-Gafoor MH, Dhooma N, Reddi A. Conservative management of thoracobiliary fistula. Ann Thorac Surg. 2002; 73:1088-91.

2. Chua HK, Allen MS, Deschamps C, Miller DL, Pairolero PC. Bronchobiliary fistula: principles of management. Ann Thorac Surg. 2000; 70:1392-4.

3. Hoffman BJ, Cunningham JT, Marsh WH. Endoscopic management of biliary fistulas with small caliber stents. Am J Gastroenterol. 1990;85: 705-7.

4. Singh B, Moodley J. Author reply to comment on Ann Thorac Surg. 2002;73:1088-91 [letter]. Ann Thorac Surg. 2004;78:1513.

5. Oparah SS, Mandal AK, Traumatic thoracobiliary (pleurobiliary and bronchobiliary) fistulas: clinical and review study. J Trauma. 1978;18: $539-44$. 